\title{
Pre-eclampsia and dyslipidaemia a case control study: an experience of tertiary healthcare centre in central India
}

\author{
Yadav BS ${ }^{1}$, Jain $S^{2}$, Toppo $\mathbf{N}^{3}$, Dehariya $\mathrm{C}^{4}$ \\ ${ }^{1}$ Dr. Bhagwan Singh Yadav, Assistant Professor, Department of Pathology, ${ }^{2}$ Dr. Sharad Kumar Jain, Associate Professor, \\ Department of Pathology, ${ }^{3}$ Dr. Neelam Anupama Toppo, Associate Professor, Department of Community Medicine, \\ ${ }^{4}$ Dr. Chanchlesh Dehariya, Post Graduate, Department of Pathology, all authors are affiliated with NSCB Medical \\ College Campus Jabalpur, MP, 482003, India.
}

Corresponding Author: Dr. Bhagwan Singh Yadav, Email: drbhagwan4@gmail.com

\begin{abstract}
Introduction: Pre-eclampsia is a multisystem disorder of pregnancy which is characterized by hypertension with proteinuria after 20 weeks of gestation in previously normotensive and non proteinuric pregnant women. Pre-eclampsia associated with intrauterine growth retardation, preterm birth, maternal and perinatal death. Dyslipidaemia has been shown to play a significant role in the pathogenesis of the disease and often precede linical manifestations. Objective: To compare the serum lipid profile in pre-eclampsia case and normal pregnant women and to assess its role in pre-eclampsia. Material and Method: 158 patients of which 79 pre-eclampsia (cases) and 79 (controls) were selected randomly and were matched with their gestational age in patient who Attending ANC clinic at Department of obstetrics and genecology in March 2016 to August 2017. Lipid profile was estimated by the Randoximola is a compact fully automated clinical chemistry analyser. Result: We observed that pre-eclampsia is more common in young age pregnant women with low socioeconomic status with strenuous activities. The mean age was $24.51 \pm 3.707$ years. The mean cholesterol, triglyceride, LDL, VLDL, value is analysed with control group showing significantly increase $(\mathrm{p}<0.0001)$ and HDL value significantly decreasedin pre-eclampsia patient in comparison to the normal control group $(\mathrm{p}<0.0001)$. Conclusion: Young age, nulliparity, low socio-economic status specially labour occupation, dyslipidaemic pregnant women were found to be more prone to develop pre-eclampsia. Proper history tacking, examination and estimation of lipid profile may be helpful forearly diagnosis and management of pre-eclampsia in order to prevent fetal and maternal complications especially in nulliparous women.
\end{abstract}

Key wards: Pre-eclampsia, Dyslipidaemia, Blood Presser, Tertiary canter

\section{Introduction}

Pre-eclampsia is a multisystem disorder of pregnancy which is characterized by hypertension (blood pressure $>140 / 90 \mathrm{~mm} \mathrm{Hg}$ ) with proteinuria (urinary protein excretion of $>300 \mathrm{mg}$ in 24 hours urine) after 20 weeks of gestation in previously normotensive and nonproteinuric pregnant women. Pre-eclampsia has been associated with intrauterine growth retardation, preterm birth, maternal and perinatal eath [1].

Pre-eclampsia occurs in $7-10 \%$ of pregnancies world wide. In India the incidence is reported to be high approximate $8-10 \%$ of the pregnancies women in developed countries have an average life time risk of

Manuscript received: $7^{\text {th }}$ February 2018

Reviewed: $14^{\text {th }}$ February 2018

Author Corrected: $20^{\text {th }}$ February 2018

Accepted for Publication: 26 ${ }^{\text {th }}$ February 2018 dying from pregnancy related causes of between 1 in 4000 and 1 in 10000, where as women in developing countries have a risk that is between 1 in 15 and 1 in 50 [2-3]. In non interventioned, pre-eclamptic cases may progress further to the dreaded complications like; eclampsia, HELLP syndrome, pulmonary edema, abruption placentae, postpartum circulatory collapse, acute renal failure, hepatic rupture, cerebral haemorrhage and visual disturbances including death. These conditions are also a major cause of neonatal morbidity and mortality [4].

Put forward for pre-eclampsia theories like placental ischemia, genetics, immunemaladaptation and oxidative stress have been proposed. Out of which oxidative stress theory is most widely accepted and has been linked with lipid abnormalities and vascular 


\section{Original Research Article}

dysfunction. Predominantly atherogenic LDL (low density lipoprotein) are increased in association with hyper lipidaemia in preeclampsia [5]. This study is designed to evaluate the serum lipid profile in preeclampsia women and compared them with normal pregnant women.

\section{Material and Method}

Type of study- case control.

Period of study- $1^{\text {st }}$ March 2016 to 31 Aug 2017 (1year and 6 month).

Place of study- Department of obstetrics and Gynaecology, Netaji Shubhash Chandra Bose medical college Jabalpur.

Study subjects: Total 158 patients, where 79 preeclampsia (cases) and 79 normal pregnant women in third trimester (control).

Sampling method and Source of data-Patients Attending ANC clinic at Department of obstetrics and Gynaecology who fulfill the inclusion criteria were selected by simple random sampling method for study, after obtaining the written informed consent. Study variable included Demographic data, family and personal History of pre-eclampsia, hypertension, diabetes mellitusand investigations details was recorded in the study proforma. After consent $5 \mathrm{ml}$ of blood was drawn under aseptic precaution from antecubital vein and collected in a EDTA and a plane tube.
Lipid profile was measured using the Randoximola is a compact fully automated bench-top clinical chemistry analyser.

Inclusion Criteria- All the pre-eclampsia patient (hypertension (blood pressure $>140 / 90 \mathrm{~mm} \mathrm{Hg}$ ) with proteinuria (urinary protein excretion of $>300 \mathrm{mg}$ in 24 hours urine) after 20 weeks of gestation in previously normotensive andnonproteinuric pregnant women)

\section{Exclusion criteria}

a) Age $>35$ year

b) Eclampsia

c) Obesity

d) Family history of hyperlipidaemia.

e) Diabetics before pregnancy.

f) Patient with known hypertension, Renal disorders, liver disorder, thyroid disease, collagen vascular disease, patient taking drugs which alters thyroid and lipid metabolism.

Statistical analysis- The statistical analysis was carried out by using SPSS 20 software of windows. Appropriate univariate and bivariate analysis was carried out using Student's t-test and chi-square testfor categorical data by a statistician. All means are expressed as mean \pm standard deviation and the proportion as in percentage (\%). The critical value for the significance of the results will be considered $<0.05$ level.

\section{Result}

In this present study total 158 cases were included. 79 were presented with Pre-eclampsia and 79 included as control group with normal pregnancy. Results of different risk factorsof pre-eclampsia were found as follows

1) Age wise distribution of Pre-eclampsia amongcase and control group. These cases and controls were divided in 4 groups $(<20,20-24,25-29,30-34)$.

According table no.-1high proportion ofpre-eclampsia was observed in 20-24 and25-29 years of age group compared to other groups. Mean age of pre-eclamptic patients was $24.51 \pm 3.70$ years.

2) Parity in relation of pre-eclampsia- As per the table no.2, higher $\%$ of pre-eclampsia was seen in nulliparous women (68.4\%) compared tomultiparous women (31.6\%) odd ratio 1.44 indicates nulliparous women having high risk to develop pre-eclampsia compered to multiparous women.

3) Occupational status of pre-eclampsiapatient- Graphno. 1 showing that most of the women whether Pre eclampsia or normal pregnant women mostly belonged to labour groups.

4) Blood pressure (diastolic and systolic)- As shown in table no.3 significant difference was observedin bothdiastolic and systolic bloodpressure of pre-eclampsia case and control group $(\mathrm{p}<0.0001)$.

5) Lipid profile evaluation in pre-eclampsia and control group- LDL- low density lipoprotein, VLDL-very low density lipoprotein, HDL-high density lipoprotein. 


\section{Original Research Article}

Table No 1. - Age wise distribution of Pre-eclampsia among case and control group.

\begin{tabular}{|c|c|c|c|}
\hline Age group & \multicolumn{2}{|c|}{ Group } & Total \\
\hline & Case & Control & \\
\hline$<20$ year & $4(5.10 \%)$ & $4(5.06 \%)$ & $8(5.20 \%)$ \\
\hline $20-24$ year & $37(46.80)$ & $43(54.43)$ & $78(50.64 \%)$ \\
\hline $25-29$ year & $26(32.60 \%)$ & $26(32.91 \%)$ & $50(32.64 \%)$ \\
\hline $30-34$ year & $12(15.20 \%)$ & $6(7.59 \%)$ & $18(11.70 \%)$ \\
\hline Total & $\mathbf{7 9}$ & $\mathbf{7 9}$ & $\mathbf{1 5 8}$ \\
\hline
\end{tabular}

Chi-squre 2=3.007; $<<0.05$

Table No.-2: Distribution of case and control according to Parity.

\begin{tabular}{|c|c|c|}
\hline Parity & Case & Control \\
\hline Nullipara & $54(68.4 \%)$ & $48(60 \%)$ \\
\hline Multipara & $25(31.6 \%)$ & $31(40 \%)$ \\
\hline Total & 79 & 79 \\
\hline
\end{tabular}

Odd ratio $(\mathrm{OR})=1.44$, lower $\operatorname{limit}(\mathrm{LL})=0.7428$, upper limit $(\mathrm{UL})=2.791$ Relative risk $(\mathrm{RR})=1.20$, lower limit $(\mathrm{LL})=0.94$, upper limit $(\mathrm{UL})=1.53$

Table No.-3: Distribution of case and control as per diastolic and systolic blood pressure

\begin{tabular}{|c|c|c|c|c|}
\hline S. No. & $\begin{array}{c}\text { Parameter } \\
(\mathbf{m m} \text { Hg) }\end{array}$ & $\begin{array}{c}\text { Study group } \\
(\mathbf{n = 7 9 )} \\
(\mathbf{m e a n} \pm \mathbf{S D})\end{array}$ & $\begin{array}{c}\text { Control group } \\
(\mathbf{n = 7 5}) \\
(\mathbf{m e a n} \pm \mathbf{S D})\end{array}$ & P value \\
\hline 1 & Diastolic blood pressure & $100.51 \pm 14.22$ & $73.79 \pm 6.44$ & $<0.0001$ \\
\hline 2 & Systolic blood pressure & $158.91 \pm 17.82$ & $118.22 \pm 7.11$ & $<0.0001$ \\
\hline
\end{tabular}

Table-4: Mean lipid profile of case and control group.

\begin{tabular}{|c|c|c|c|c|c|}
\hline S.No. & Parameters(mg/dl) & $\begin{array}{c}\text { Study group(n=79) } \\
(\text { mean } \pm \text { SD) }\end{array}$ & $\begin{array}{c}\text { Control group(n=79) } \\
(\mathbf{m e a n} \pm \mathbf{S D})\end{array}$ & $\begin{array}{c}\text { t }- \text { value } \\
\mathbf{A t}<\mathbf{0 . 0 5}\end{array}$ \\
\hline 1 & Cholesterol & $221.60 \pm 22.55$ & $168.10 \pm 8.70$ & 18.4644 & $<.00001$ \\
\hline 2 & Triglycerides & $243.50 \pm 32.33$ & $129.31 \pm 20.00$ & 26.25056 & $<0.0001$ \\
\hline 3 & HDL & $34.55 \pm 5.37$ & $42.96 \pm 4.35$ & 10.45444 & $<0.00001$ \\
\hline 4 & VLDL & $48.48 \pm 6.88$ & $28.77 \pm 5.13$ & 18.38615 & $<0.00001$ \\
\hline 5 & LDL & $134.44 \pm 16.96$ & $85.19 \pm 18.11$ & 21.97432 & $<0.00001$ \\
\hline
\end{tabular}

LDL- low density lipoprotein, VLDL-very low density lipoprotein, HDL-high density lipoprotein

Table No.5- Comparison of lipid profile in pre-eclampsia cases in different studies.

\begin{tabular}{|c|c|c|c|c|c|}
\hline Study & Total cholestsrol & Triglycerides & HDL & LDL & VLDL \\
\hline VANI et al[19] & $227 \pm 31$ & $219 \pm 58$ & $51 \pm 5$ & $132 \pm 34$ & $43 \pm 10$ \\
\hline $\begin{array}{c}\text { Mishra M.K. et } \\
\text { aal[20] }\end{array}$ & $236.14 \pm 5.9$ & $287.1 \pm 3.7$ & $39.95 \pm 1.3$ & $147.64 \pm 4.2$ & $57.72 \pm 0.82$ \\
\hline Gohil J. T. et al[2] & $232.0 \pm 2.9$ & $270 \pm 2.1$ & $42.1 \pm 1.9$ & $135.8 \pm 4.1$ & $54.1 \pm 0.31$ \\
\hline Present study & $221.60 \pm 22.55$ & $243.50 \pm 32.33$ & $34.55 \pm 5.37$ & $134.44 \pm 16.96$ & $48.48 \pm 6.88$ \\
\hline
\end{tabular}


Original Research Article

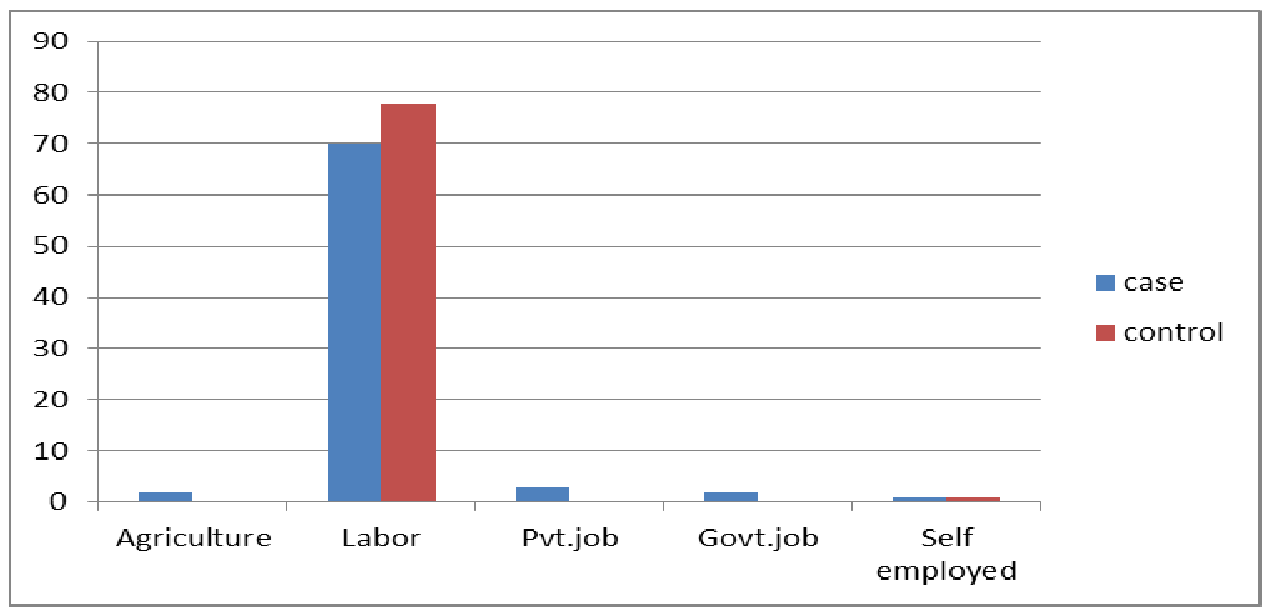

Figure- 01: Relative Risk of different Occupation in Pre-eclampsia patient.

As shown in table no.4 the mean cholesterol, triglyceride, VLDL, LDL value were calculated in case and control group, showing significantly high cholesterol, triglyceride, VLDL, LDL in pre-eclampsia compared to the control group. This difference was statically significant as $\mathrm{p}$ value was found $<0.0001$. HDL value is analysed with control group showing significantly decrease in pre-eclampsia in comparison to the normal control group $(\mathrm{p}<0.0001)$.

\section{Discussion}

Pre-eclampsia adversely affects the maternal and fetal outcome due to its wide spread multi organ involvement. In our study we have observed a correlation between lipid profileand the development of pre-eclampsia. In this present study we found preeclampsia more prevalent among patient in age group 20 to $25(46.80 \%)$. Similar finding reported by Zibaeenaz had et al, Sheraz et al, Kumar et al, and Duckitt et al [6-9]

The Factor influencing the development of Preeclampsia before 20 years of age as reported by walker may be due to initial trophoblastic invasion and how the mother reacts to it. The failure of the normal invasion of trophoblastic cells leads to mal adaptation of the spiral arterioles, which are related to the causation of preeclampsia [10].

Pre-eclampsia is often experienced by young and nulliparous women, where as the older women at risk for having chronic hypertension with superimposed preeclampsia. The incidences of pre-eclampsia in multiparous women was also varied but lower than nulliparaous [11]. In our study we found that nulliparous women had 1.20 times higher risk of preeclampsia than to multiparous women $(\mathrm{OR}=1.44$, $\mathrm{RR}=1.20$ ). Similar finding reported by Opitasariet al with relative risk 1.78 , Lee et al in Taiwan reported relative risk was 1.3 and Luealon in Thailand found that null parity increased the risk of pre-eclampsia 3.8 times, while in another study in India revealed that parity was not found to be associated with pre-eclampsia [12-15].
As per the figure 01 Present study suggesting an association between the low socio-economy with preeclampsia as most of the women belong to labour class. It is evident that, the labour class with strenuous work had high risk of having pre eclampsia. The possible causes of high incidence of pre-eclampsia in this group could be illiteracy, un-awareness, and poor approach to medical aid etc. This finding is similar to what was found by Abubakar Attahir et al and Dlamini et al. They found that poverty in adults is associated with severity and risk of developing pre-eclampsia among women in developing countries. Our finding is distinct with the studies of Gudmundssone et al who found that the risk and severity of pre-eclampsia is not associated with poverty among women of developed country [16-18].

As shown in table no.3 significant difference was observed in both diastolic and systolic blood pressure of pre-eclampsia case and control group $(\mathrm{p}<0.0001)$. Similar finding was also seen by Abubakar attahir et al 16 where systolic and diastolic blood pressure was significantly different. (167.60 \pm 2.75 and $107.48 \pm 8.01$ Vs. $116.70 \pm 0.98$ and $76.80 \pm 8.67$ in group B Vs. group A respectively, $\mathrm{P}<0.05$ ). In our study the mean levels of cholesterol, TG, LDL and VLDL were significantly higher in pre-eclamptic women than in normotensive controls $(\mathrm{p}<0.05)$. Also there was a significant decrease in HDL in study group as compared to control $(\mathrm{p}<0.05)$.

Different parameters of lipid profile of pre-eclampsia patients in different studies shows same pattern as seen in present study (Table $4 \& 5$ ). 


\section{Original Research Article}

Pre-eclampsia is a complex patho physiological process where regulatory systems of inflammation and endothelial function are stimulated beyond the physiological limits of normal pregnancy [21]. Abnormal lipid metabolism is also involved in pathogenesis of disease [22]. If pre-eclampsia is multi causal disease, then TG-related vasculopathy may be one possible etiological factor [21]. Women with preeclampsia have higher levels of circulating serum triglycerides which is an essential step in lipid mediated endothelialdys function. The mechanisms driving the abnormal elevation of triglycerides leading to preeclampsia are unclear.

During pregnancy, there is an increase in the hepatic lipase activity and decrease in lipoprotein lipase activity. Hepatic lipase is responsible for the increased synthesis of the triglycerides at the hepatic level, and the decreased activity of lipoprotein lipase is responsible for the decreased catabolism at the adipose tissue level, where as placental VLDL receptors are up regulated. This results in re-routing of TG rich lipoproteins to the feto-placental unit [2].

Hyper triglyceridemia predispose woman to preeclampsia due to increased serum lipoprotein levels during pregnancy and these levels increases up two folds in pre-eclampsia patientsand serum triglyceride concentration levels rises more significantly in preeclampsia [23]. It may be due to insulin resistance, hyper lipidaemia and up-regulation of inflammatory mediators. In pregnancy the oestrogen levels are very high and this hyper estrogenemia is responsible for hyper triglyceridemia.

The increased levels of triglyceride are related with hyper coagulability [24]. Altered lipid synthesis leading to decreased in Prostaglandin I2 (PGI2): Thromboxane A2 (TXA2) ratio is also supposed to be an important way of pathogenesis in pre-eclampsia [25].

Others researchers have observed higher concentrations of total cholesterol, phospholipids and lipid peroxides in placental decidual tissue derived from women with preeclampsia. They also found thatthe layer of the placenta that contains the spiral arteries and where the process of atherosis may increase the risk of placental vascular disease [26].

Clearly, there is a need to establish whether preconception dietary modification can reduce the future risk of pre-eclampsia and other placentamediated diseases, including placental abruption and fetal intrauterine growth restriction. Study conducted by Kashinakunti et al concludes that there is a positive correlation between serum triglycerides and systolic blood pressure and diastolic blood pressure in preeclampsia cases [22]. Elevated maternal triglyceride levels measured during early pregnancy are associated with pregnancy complications and adverse pregnancy outcomes. These results suggest that future lifestyle programs in women of reproductive age with a focus on lowering triglyceride levels (i.e. diet, weight reduction, and physical activity) may help to prevent hypertensive complications during pregnancy and adverse birth outcomes [27].

VLDL transports $\mathrm{TG}$ in peripheral blood therefore hyper triglyceridemia also leads to increased serum levels of VLDL [28]. Insulin resistance causes lipolysis, leading to increased flux of fatty acids to liver promoting synthesis of VLDL [29]. Increased LDL levels are due to elevated oestrogen and progesterone levels in preeclampsia. It has been shown that LDL (specially oxidized LDL) increases arterial sensitivity to presser agents and inhibits endothelium dependant vasodilatation. This endothelial dysfunction, leads to glomerular lesions and it leads proteinuria, which is anindication of severity of pre-eclampsia [5].

Low HDL in Pre-eclampsia is due to insulin resistance [23]. According to Pirzado et al, there is a direct correlation between adipose tissue lipoprotein lipase activity and plasma HDL. This is responsible for low levels of HDL [30].

This HDL cholesterol is involved in exchange of cholesterol, cholesterol esters and triglycerides from peripheral tissues to the liver (reverse cholesterol transport) where they are metabolised and excreted. It also involve in activating lipoprotein which releases fatty acids that can be oxidised by $\beta$ oxidation pathway to provide energy. Low levels of HDL-Cholesterol may compromise the function of all these processes[2].

\section{Conclusion}

Our study revealed abnormal lipid profile in preeclampsia group compared to control group. Therefore we can conclude that simple estimation of lipid profile may be helpful in the early diagnosis and management to prevent fetal and maternal complications especially in nulliparous women. There is a need forfurther studies withlarge size sample tovalidate these facts.

Funding: Nil, Conflict of interest: None initiated Permission from IRB: Yes 


\section{Original Research Article}

\section{References}

1. Sibai B, Dekker G, Kupferminc M. Pre-eclampsia. Lancet. 2005 Feb 26-Mar 4;365(9461):785-99.

2. Gohil JT, Patel PK, Gupta P. Estimation of lipid profile in subjects of preeclampsia. J Obstet_Gynaecol India. 2011 Aug; 61 (4):399-403. doi: 10.1007/s13224011-0057-0. Epub 2011 Sep 22.

3. Duley L. Maternal mortality associated with hypertensive disorders of pregnancy in Africa, Asia, Latin America and the Caribbean. Br J Obstet_Gynaecol. 1992 Jul; 99(7):547-53.

4. Fernando A, Shrish ND, Amarnath GB. Hypertensive disorders of pregnancy. Practical guide to high risk pregnancy and delivery; 3rd edition: P. 398.

5. Enaruna NO, Idemudia JO, Aikoriogie PI. Serum lipidprofile and uric acidlevels in preeclampsia in University of Benin Teaching Hospital. Niger Med J.2014 Sep; 55 (5): 423-7. doi: 10. 4103/0300-1652. 140387.

6. Zibaeenaz had MJ, Ghodsi M, Arab P, Gholzom N. The prevalence of hypertensive disorders of pregnancy in Shiraz, Southern Iran. Iranian Cardiovascular Research Journal.2010;4:169-72.

7. Sheraz S, Shahzad S, Boota M. Eclampsia. Professional Medical Journal. 2006;13(1):27-31.

8. Kumar R, Gandhi S, Rao V. Socio-Demographic and Other Risk Factors of Pre Eclampsia at a Tertiary Care Hospital, Karnataka: Case Control Study. Journal of Clinical and Diagnostic Research.2014;8(9):1-4.

9. Duckitt K, Harrington D. Risk factors for preeclampsia at antenatal booking: systematic review of controlled studies. BMJ. 2005 Mar 12; 330 (7491):565. Epub 2005 Mar 2.

10. Walker JJ. Severe pre-eclampsia and eclampsia. Baillieres Best Pract Res Clin Obstet_Gynaecol. 2000 Feb; 14 (1):57-71.

11. Cunningham GF, Leveno KJ, Bloom SL, et al. William's obstetrics. 23rd ed. Cambridge university press 2010; p. 706-47

12. Opitasari C, And ayasari L . Parity, education level and risk for (pre-) eclampsia in selected hospitals in Jakarta. Health Science Indones .2014; 1:35-9
13. Lee CJ, Hsieh TT, Chiu TH, Chen KC, Lo LM, Hung TH. Risk factors for pre-eclampsia in an Asian population.Int J Gynaecol Obstet. 2000 Sep; 70 (3): 327-33

14. Luealon P, Phupong V. Risk factors of preeclampsia in Thai women. J Med Assoc Thai. 2010 Jun; 93 (6): 661-6.

15. Agrawal, S. and Walia, G.K. (2010) Prevalence and Risk Factors for Pre-Eclampsia in Indian Women: A National Cross Sectional Study. South Asia Network for Chronic Disease, Public Health Foundation of India, New Delhi.

16. Abubakar A, Dikko A, Sufiyan MB, Salihu A, Rabiu A. Association between Maternal Socioeconomic Status, Polygamy and Risk of Pre eclampsia in Rural Areas of Northern Nigeria Journal of Family and Reproductive Health. 2010;4(1):47-52.

17. Dlamini NJ. Factors associated with pre-eclampsia and quality care of affected teenagers during labour within health region $\mathrm{H}$. in Kwa-Zulu Natal. Curationis. 1997 Dec; 20 (4):16-22.

18. Gudmundsson S, Bjorgvinsdottir L, Molin J, et al. Socioeconomic status and perinatal outcome according to residence area in the city of Malmo. Acta Obstet Gynecol Scand.1997; 76: 318-23.

19. Vani I, Gayathri A, Nagamani T and Sunieeta H. (2015). Lipid profile parameters in normal and preeclampsia complicating pregnancies - A prospective observational study. The Ame J Sci \& Med Res, 1 (1): 61-66. doi: 10. 17812/ ajsmr 201 5114.

20. Misra MK, Tiu DN, Sharma R. Lipid profile in preeclampsia in comparison with normal subjects. Int $\mathbf{J}$ Med Res Rev 2016;4(10):1859-1862.

21. Tripathy C, Malik S, Shah P, Lakshmy R, Tripathy D. Serum insulin and lipid profile in normal pregnant and pregnancy-induced hypertensive women from North India. Aust N Z J Obstet Gynaecol. 1999 Aug;39 (3): 321-3.

22. Kshinakunti SV, Sunitha H, Gurupaddappa K, Manjula R. Lipid Profile In Preeclampsia - A Case Control Study. Journal of Clinical and Diagnostic Research. 2010 Aug;4:2748-2751. 


\section{Original Research Article}

23. Cekmen MB, Erbagci AB, Balat A, Duman C, Maral H, Ergen K, et al. Plasma lipid and lipoprotein concentrations in pregnancy induced hypertension. Clin. Biochem. 2003; 36(7): 575-8.

24. Kokia E, Barkai G, Reichman B, Segal P, Goldman B, Mashiach S. Maternal serum lipid profile in pregnancies complicated by hypertensive disorders. J Perinat Med. 1990;18(6):473-8.

25. Das S, Char D, Sarkar S, Das P, Saha TK, Biswas S. Comparison of lipid profiles in normal pregnancy and in pre-Eclampsia: A case control study. IOSR Journal of Dental and Medical Sciences. 2013; 11(4): 53-55.

26. RayJG, Diamond P, Singh G, Bell CM. Brief overview of maternal triglycerides as a risk factor for pre-eclampsia. BJOG 2006; 113 (4): 379-86. doi.10. 1111/j. 1471-0528.2006.00889.x

27. Vrijkotte TG, Krukziener N, Hutten BA, Vollebregt KC, van Eijsden M, Twickler MB. Maternal lipidprofile during early pregnancy and pregnancy complications and outcomes: the ABCD study. J Clin Endocrinol Metab. 2012 Nov; 97 (11): 3917-25. doi: 10.1210/jc. 2012-1295. Epub2012 Aug 29.

28. Ephraim RKD, Doe PA, Amoah S, Antoh EO. Lipid profile and high maternal body mass index is associated with preeclampsia: A case-control study of the Cape Coast Metropolis. Ann Med Health Sci Res. 2014 Sep-Oct; 4(5): 746-750.doi: 10.4103/2141-9248. 141542

29. Islam N, Chowdhury M, Kibria GM, S Akhter Faridpur. Study of serum lipid profile in pre-eclampsia and eclampsia. Med. Coll. J. 2010; 5 (2):56-59. doi: 10. 3329/fmcj.v5i2.6823.

30. Pirzado ZA, Sangi SA, Malik R. High density lipoprotein cholesterol metabolis and its role in ischemic heart disease. Pak J Med Res 1999; 38 (1): $38-41$.

\section{How to cite this article?}

Yadav BS, Jain S, Toppo N, Dehariya C. Pre-eclampsia and dyslipidaemia a case control study: an experience of tertiary healthcare centre in central India. Trop J Path Micro 2018;4(1):121-127. doi: 10.17511/jopm.2018.i1.22 